\title{
Utility of silver-nanoparticles for nano-fluorimetric determination of vancomycin hydrochloride in pharmaceutical formulation and biological fluids: Greenness assessment
}

Ahmed R. Mohamed ( $\sim$ arabih48@gmail.com )

Egyptian Russian University https://orcid.org/0000-0002-7874-6334

\section{Research Article}

Keywords: Vancomycin hydrochloride, Silver nanoparticles, Spectrofluorimetry, Biological fluids, Ecoscale, Green analytical procedure index

Posted Date: February 3rd, 2022

DOI: https://doi.org/10.21203/rs.3.rs-1302164/v1

License: (9) This work is licensed under a Creative Commons Attribution 4.0 International License. Read Full License 


\section{Abstract}

Vancomycin hydrochloride (VANH) is a glycopeptide antibiotic commonly employed in the prophylaxis and therapy of various gram-positive bacterial life-threatening infections. Due to the narrow therapeutic window of VANH, its serum levels should be well-monitored to avoid toxicity and optimize its therapy. Herein, an innovative silver-nanoparticles enhanced fluorescence technique was designed for VANH rapid analysis in miscellaneous matrices. This technique is based on reinforcement of VANH fluorescence intensity with silver-nanoparticles that were synthesized by a redox reaction between VANH and silver nitrate in $\mathrm{NaOH}$ alkaline medium using polyvinylpyrrolidone as a stabilizer. The produced silvernanoparticles were characterized by using UV-visible spectroscopy and transmission electron microscope (TEM) micrograph. The fluorescence intensity was measured at $394 \mathrm{~nm}$ after excitation at $259 \mathrm{~nm}$. Under optimum conditions, a good linear relationship was accomplished between the VANH concentration and the fluorescence intensity in a range of (1-36) $\mathrm{ng} / \mathrm{mL}$ with a limit of detection of $0.29 \mathrm{ng} / \mathrm{mL}$. Greenness assessment was performed using two assessment tools namely; eco-scale scoring and green analytical procedure index revealing excellent greenness of the proposed technique. The proposed technique was validated according to $\mathrm{ICH}$ recommendations and statistically compared with the reported HPLC method revealing no significant difference concerning accuracy and precision at $p=0.05$. The proposed technique depended primarily on the water as a cheap and eco-friendly solvent consequently; it's regarded as a green alternative to the expensive chromatographic techniques that utilize hazardous organic solvents. Furthermore, the attained ultrasensitivity of the proposed technique can be adapted for VANH monitoring and studying its bioequivalence in biological fluids.

\section{Introduction}

Silver-nanoparticles (Ag-NPs) have wide-ranging antimicrobial activities besides their prodigious uses in numerous fields especially those related to drug delivery and analysis. In the field of drug delivery, Ag-NPs are utilized to direct the drugs to the diseased tissues consequently, improving the therapeutic efficacy and minimizing the potential side effects of drugs particularly in the field of chemotherapy [1]. In the field of drug analysis, Ag-NPs are utilized to develop many sensitive and green techniques for the determination of drugs at the lowest cost due to their primary dependence on the water as a cheap and green solvent [2]. Furthermore, the AgNPs-enhanced fluorescence technique is a promising trend in today's spectrofluorimetric experiments. Fluorescence enhancement is effectively used to improve the techniques sensitivity and detection limits to nano-levels to be more convenient for quantitative drug analysis in miscellaneous matrices at ultra-trace levels.

VANH presented in Fig. 1, is a glycopeptide antibiotic commonly utilized in the prophylaxis and therapy of various gram-positive bacterial life-threatening infections especially those provoked by methicillinresistant staphylococci. The potency of VANH is due to its capability to impede the peptidoglycan polymers' synthesis of bacteria's cell wall resulting in bacterial death. Hence, VANH therapy is the first and last resort of defense against serious bacterial infections when other medications have failed due to bacterial resistance or patient sensitivity, especially sensitivity to $\beta$-lactam antibiotics. Due to the narrow 
therapeutic window of VANH, the under-dosing of VANH leads to insufficient bacterial eradication and developing of antibiotic-resistant bacteria while the over-dosing is primarily correlated with nephrotoxicity and ototoxicity [3]. So, VANH concentration levels should be well-monitored not only in the biological fluids but also in the pharmaceutical commercial products to avoid toxicity or side effects and to optimize VANH therapy.

According to the literature survey, some techniques were reported for the estimation of VANH in different matrices including spectrophotometric [4-6], spectrofluorimetric [7-9], electrochemical [10-12], HPLC [13-21], LC-MS/MS [22-33], capillary electrophoresis [34-37], radioimmunoassay and ELISA-based immunoassay techniques [38-40]. VANH has native fluorescence at $335 \mathrm{~nm}$ after excitation at $268 \mathrm{~nm}$ according to this study [8]. Hence, the purpose of this research is to introduce novel ultrasensitive, simple, cost-effective, and time-saving AgNPs-enhanced fluorescence technique for VANH rapid analysis in its pharmaceutical formulation and biological fluids without interference by the additives of its pharmaceutical formulation or by the matrix of biological fluids yielding satisfactory recovery results comparable to those of the reported HPLC platform [21]. The synthesized Ag-NPs were characterized by using UV-visible spectroscopy and transmission electron microscope (TEM) micrograph. The proposed technique is regarded as a green method for rapid assay of VANH in miscellaneous matrices due to its dependence primarily on the water as a cheap and eco-friendly solvent relative to the other expensive and hazardous organic solvents utilized in most of the reported techniques. Furthermore, the proposed technique's ultrasensitivity can be adapted for therapeutic monitoring of VANH and studying its bioequivalence in biological fluids.

Greenness assessment of the utilized reagents and procedure was performed to evaluate the proposed technique greenness by using two tools namely; eco-scale scoring and green analytical procedure index revealing excellent greenness of the proposed technique.

\section{Experimental}

\subsection{Materials and chemicals}

All chemicals and reagents used during this study were of analytical grade; bi-distilled water was utilized throughout the study.

- The standard of VANH was kindly supplied from Sigmatec Pharmaceutical Industries (Giza, Egypt) with a purity of $99.61 \%$ according to the manufacturer's purity certificate.

- Methanol, acetonitrile, ethanol, 2-propanol, boric acid, phosphoric acid, glacial acetic acid, and acetone (Adwic, Egypt).

- Sodium hydroxide, $\left(5 \times 10^{-3} \mathrm{M}\right.$ and $\left.2 \times 10^{-1} \mathrm{M}\right)$ aqueous solutions (Adwic, Egypt).

-Britton-Robinson buffer solutions ( $\mathrm{pH} 2-12)$ were prepared by mixing different volumes of $(0.04 \mathrm{M}$ phosphoric acid, $0.04 \mathrm{M}$ acetic acid, and $0.04 \mathrm{M}$ boric acid) solutions; $\mathrm{pH}$ of the buffer solutions was adjusted to the required $\mathrm{pH}$ using a $0.2 \mathrm{M} \mathrm{NaOH}$ aqueous solution. 
- Silver nitrate, $\left(3 \times 10^{-3} \mathrm{M}\right)$ aqueous solution (Sigma-Aldrich), should be freshly prepared and protected from light during use.

- Polyvinylpyrrolidone, (0.14\%) aqueous solution (Sigma-Aldrich).

- Human plasma and urine samples were kindly supplied from Zagazig University Hospitals (Sharqia, Egypt), and preserved at $-20^{\circ} \mathrm{C}$ until the analysis time.

\subsection{Pharmaceutical formulation}

Vancomycine® Mylan vial; manufactured by Biologici Italia Laboratories S.R.L. (Milan, Italy); batch number (B1527); labeled to contain $500 \mathrm{mg}$ of VANH.

\subsection{Instruments}

Fluorescence spectrometer FP-6200 (Jasco, Japan), supplied with a 150-Watt Xe-arc lamp and 1-cm quartz cell was used. At $10 \mathrm{~nm}$, slit widths for both monochromators were set. The fluorimetric measurements were carried out at medium sensitivity using spectra manager software v1.54.

Jasco model V-630 (Japan) double beam UV-visible spectrophotometer with two matched 1-cm quartz cells, connected to an ACER compatible PC with spectra manager II software was utilized to characterize the spectrum of the prepared Ag-NPs.

A JEOL-1010 transmission electron microscope (TEM, Japan) at $80 \mathrm{kV}$ was employed to characterize the size and morphology of the prepared Ag-NPs.

Sonicator (Model WUC-A06H), vortex mixer (Model VM-300), rotary evaporator (Model Scilogex RE 100pro), and benchtop centrifuge (Model K241R) were utilized.

\subsection{Standard solution}

Stock standard solution $(100 \mu \mathrm{g} / \mathrm{mL})$ was prepared by dissolving $10 \mathrm{mg}$ of pure VANH in $70 \mathrm{~mL}$ bidistilled water into a $100-\mathrm{mL}$ volumetric flask using the sonicator for 5 minutes. Subsequently, the volume was totaled to the $100-\mathrm{mL}$ mark using the same solvent.

Working standard solution $(1 \mu \mathrm{g} / \mathrm{mL})$ was prepared by transferring $1 \mathrm{~mL}$ of the stock solution into a 100$\mathrm{mL}$ volumetric flask and then completed to the $100-\mathrm{mL}$ mark with bi-distilled water.

The standard solution was estimated to be stable for 7 days when preserved in the refrigerator as it exhibited no chromatographic or absorbance changes.

\section{General Procedure}

\subsection{Preparation of Ag-NPs and construction of calibration plot}


By using a micropipette, aliquots of VANH were accurately transferred from its working standard solution $(1 \mu \mathrm{g} / \mathrm{mL})$ followed by the addition of $1.2 \mathrm{~mL}$ of $\mathrm{AgNO}_{3}\left(3 \times 10^{-3} \mathrm{M}\right), 1 \mathrm{~mL}$ of PVP $(0.14 \%)$, and $1.2 \mathrm{~mL}$ of $\mathrm{NaOH}\left(5 \times 10^{-3} \mathrm{M}\right)$ solutions into a series of $10-\mathrm{mL}$ volumetric flasks. The prepared solutions were heated for $20 \mathrm{~min}$ in a water bath that was thermostatically controlled at $90^{\circ} \mathrm{C}$. As a result, Ag-NPs were formed. After cooling the solutions to room temperature, $1 \mathrm{~mL}$ of Britton-Robinson buffer solution $(\mathrm{pH}=6)$ was added. Subsequently, the volumes were totaled using bi-distilled water to the $10-\mathrm{mL}$ mark to prepare final concentrated solutions in the range $(1-36) \mathrm{ng} / \mathrm{mL}$. The fluorescence intensity values were measured at $394 \mathrm{~nm}$ after excitation at $259 \mathrm{~nm}$ versus reagent blank handled similarly and concurrently without VANH (Table 1). Each prepared solution was measured three times.

Table 1

The optimized analytical parameters required for the determination of VANH by the proposed fluorimetric method.

\begin{tabular}{|ll|}
\hline Parameters & Optimized values \\
\hline$\lambda_{\text {excitation }}(\mathrm{nm})$ & 259 \\
$\lambda_{\text {emission }}(\mathrm{nm})$ & 394 \\
\hline $\mathrm{AgNO}_{3}\left(3 \times 10^{-3} \mathrm{M}\right)$ volume $(\mathrm{mL})$ & 1.20 \\
\hline $\mathrm{PVP}(0.14 \%)$ volume $(\mathrm{mL})$ & 1 \\
\hline $\mathrm{NaOH}\left(5 \times 10^{-3} \mathrm{M}\right)$ volume $(\mathrm{mL})$ & 1.20 \\
\hline Heating time $(\mathrm{min})$ at $90^{\circ} \mathrm{C}$ & 20 \\
\hline Britton-Robinson buffer $(\mathrm{pH}=6)$ volume $(\mathrm{mL})$ & 1 \\
\hline
\end{tabular}

The calibration plot was constructed by relating the fluorescence intensity values to the corresponding VANH concentrations in $\mathrm{ng} / \mathrm{mL}$ followed by computing the regression equation.

\subsection{Application to the pharmaceutical formulation}

From Vancomycine ${ }^{\circledR}$ Mylan vial, an accurately weighed mass equivalent to $10 \mathrm{mg}$ of VANH powder was transferred into a $100-\mathrm{ml}$ volumetric flask containing $70 \mathrm{ml}$ bi-distilled water and subsequently sonicated for 5 minutes. The solution volume after sonication was totaled to the 100-ml mark using bi-distilled water. From the obtained solution, $1 \mathrm{~mL}$ was transferred into another $100-\mathrm{mL}$ volumetric flask and then completed to the $100-\mathrm{mL}$ mark using the same solvent to obtain $(1 \mu \mathrm{g} / \mathrm{mL})$ as a working solution. Finally, the assay was performed as presented before under the general procedure of Ag-NPs preparation to compute the nominal content of VANH in commercial vials and to apply the technique of standard addition.

\subsection{Application to spiked biological fluids}


To a series of centrifugation tubes, accurately measured aliquots corresponding to $1-\mathrm{mL}$ of thawed drugfree human plasma or urine at room temperature were transferred. Then, different aliquots of VANH working standard solution $(1 \mu \mathrm{g} / \mathrm{mL})$ were spiked into the centrifugation tubes and blended well with 3 $\mathrm{mL}$ methanol for 3 minutes by the vortex mixer for denaturation and precipitation of proteins. For another 20 minutes at $5000 \mathrm{rpm}$, the solutions were centrifuged for separation of the precipitated proteins or any insoluble particulate. The clear supernatants were carefully separated and evaporated to dryness by the rotary evaporator. The residues after drying were reconstituted using $3 \mathrm{~mL}$ bi-distilled water and transferred directly into a series of $10-\mathrm{mL}$ volumetric flasks. Subsequently, the solutions were handled as declared before under the general procedure of Ag-NPs preparation to obtain final concentrations within the range (1-36) $\mathrm{ng} / \mathrm{mL}$. Blank samples were prepared concurrently by the same procedure without VANH. The prepared concentrations of VANH in urine or plasma were computed finally from the calibration plot.

\section{The Reported Method}

An HPLC-UV method [21] was reported for quantitative analysis of VANH in different biological matrices at $215 \mathrm{~nm}$ on a Cortecs ${ }^{\circledR} \mathrm{C}_{18}$ column using a mobile phase consisting of $20 \mathrm{mM}$ phosphate buffer containing $0.5 \% \mathrm{v} / \mathrm{v}$ of triethylamine $(\mathrm{pH} 2.5)$ and a mixture of methanol-acetonitrile $(70: 30, \mathrm{v} / \mathrm{v})$. The results of the proposed fluorimetric technique and reported HPLC method were statistically compared for evaluating the efficiency of the proposed technique.

\section{Evaluation Of Method Greenness}

Two novel approaches were presented to assess the greenness of the proposed method with the reported HPLC method called analytical eco-scale [41, 42] and green analytical procedure index [43].

Analytical eco-scale is a useful semi-quantitative tool used to evaluate any analytical methodology's greenness. It relies on calculating the penalty points of two main parameters of the analytical procedure. The first parameter is known as the reagent parameter that can be computed by concerning amounts, environmental, physical, and health hazards of the used reagents. The second parameter is related to the instrumentation including the instrument's energy consumption, occupational hazards, and amount of waste generated by the device. After computing the penalty points assigned to the aforementioned parameters, the results are subtracted from 100 to obtain the total score required for the greenness assessment. The ideal analytical method is given 100 on the eco-scale score. According to the total score value, the method is considered as an excellent or acceptable, or inadequate green method.

In Table 2, the calculated penalty points for the proposed method were 19 points while were 29 points for the reported HPLC method revealing the excellent greenness of the proposed method. Also, these results confirm the superiority of the proposed method procedure over the reported method due to lower consumption of chemicals and energy as well as lower waste generation. 
Table 2

Results of eco-scale analysis for the determination of VANH employing the proposed fluorimetric method and the reported HPLC method.

$\begin{array}{lll}\text { Methods } & \text { Proposed fluorimetric method Reported HPLC method [21] } \\ \text { Parameters } & \end{array}$

\section{Reagents}

Methanol

6

12

Acetonitrile

$-$

4

Triethylamine

$-$

6

$\mathrm{AgNO}_{3}$

0

PVP

0

$\mathrm{NaOH}$

2

Boric acid

2

Phosphoric acid

2

Glacial acetic acid

4

Instruments

Spectrophotometer/HPLC

Energy

[ $\leq 0.1 \mathrm{kWh} /$ sample]

[>0.1 kWh/sample]

Occupational hazard

0

0

Waste

3

6

Total penalty points

$\Sigma 19$

$\Sigma 29$

Analytical eco-scale total score ${ }^{a, b}$

81

71

Excellent green analysis

Acceptable green analysis

a Analytical eco-scale total score $=100-$ total penalty points .

b If the score is $>75$, it indicates excellent green analysis.

If the score is $>50$, it indicates acceptable green analysis.

If the score is $<50$, it indicates inadequate green analysis.

Another tool for greenness assessment of analytical process is green analytical procedure index (GAPI). GAPI is a more advanced tool for greenness assessment. Fifteen-segment pictograms represent different 
aspects of the analytical process from sample preparation to the final detection. Each segment includes three color-specific codes (green, yellow, or red) to indicate the high, medium, or low environmental impact of each step of the analytical methodology. Figs. 2 and 3 showed the greenness assessment profile for the proposed and reported methods' procedures using the GAPI tool, revealing the superiority of the proposed method procedure over the reported method.

Consequently, the proposed fluorimetric method excels over the reported HPLC method as a greener alternative for the quantitative analysis of VANH in its pharmaceutical formulation and biological fluids.

\section{Results And Discussion}

VANH as a potent glycopeptide antibiotic has an extraordinary role not only in the prophylaxis but also in the therapy of various gram-positive bacterial life-threatening infections. In synthesis or analysis, the majority of laboratories worldwide are moving nowadays towards green chemistry to decrease impacts on the environment and to improve the health safety of analysts. So, a novel ultrasensitive and simple AgNPs-enhanced fluorescence technique was presented for VANH rapid analysis in its pharmaceutical formulation and biological fluids yielding satisfactory recovery results comparable to those of the reported HPLC technique [21].

In the present effort, the reaction system involved an aqueous $\mathrm{AgNO}_{3}$ solution in $\mathrm{NaOH}$ alkaline medium with PVP as a stabilizer to prevent agglomeration of Ag-NPs after their synthesis. The addition of VANH as a reducing agent to the reaction mixture led to reduction of the silver ions to a stoichiometrically equivalent quantity of golden yellow Ag-NPs with high fluorescence intensity and intriguing optical properties (Fig. 4). So, the fluorescence signal of VANH was greatly intensified upon the synthesis of AgNPs-enhanced fluorescent solution. The nano-detection of VANH can be achieved by measuring the fluorescence intensity of the prepared Ag-NPs solution at $394 \mathrm{~nm}$ after excitation at $259 \mathrm{~nm}$ against the blank reagent (Fig. 5). The fluorescence intensity was observed to be linearly dependent on the concentration of VANH.

The synthesized Ag-NPs were characterized by UV-visible spectroscopy and TEM micrograph. As illustrated in Fig. 6, the Ag-NPs exhibited a characteristic spectrum with an intense absorption maximum at $415 \mathrm{~nm}$ due to the surface plasmon excitation. It was observed that VANH absence from the reaction system resulted in absence of any absorption peak in the visible region $(400-700 \mathrm{~nm})$. Also, the formation of Ag-NPs in presence of VANH was confirmed as presented in Fig. 7 by the TEM micrograph which reveals that the Ag-NPs were spherical in shape with smooth surface morphology and size of $10.74 \pm 2.44 \mathrm{~nm}$.

Unlike conventional fluorimetric methods, the proposed method is highly sensitive enough to measure VANH concentrations at ultra-trace quantities and consequently, can be adapted for VANH monitoring and studying its bioequivalence in biological fluids. The proposed method is regarded as a green fluorimetric 
technique appropriate for VANH analysis in miscellaneous matrices at a low cost due to its dependence mainly on water as a cheap and eco-friendly solvent.

\subsection{Method optimization}

To obtain optimum results of the proposed technique for the determination of $\mathrm{VANH}$, the following variables were studied:

\subsubsection{Effect of concentration and volume of $\mathrm{AgNO}_{3}$ solution}

Several experiments were performed on differently concentrated solutions of $\mathrm{AgNO}_{3}$ using the same concentration of VANH in each trial at other optimal reaction conditions (Table 1). As a result, it was observed that $\mathrm{AgNO}_{3}\left(3 \times 10^{-3} \mathrm{M}\right)$ solution was the best one for optimum results, after which the increase in the concentration of $\mathrm{AgNO}_{3}$ solution resulted in a significant decrease in the fluorescence intensity of $\mathrm{Ag}-\mathrm{NPs}$ due to the formation of $\mathrm{AgCl}$ white precipitate. Afterward, different volumes of $\mathrm{AgNO}_{3}$ solution $\left(3 \times 10^{-3} \mathrm{M}\right)$ were tried at the same reaction conditions. The results revealed that $1.2 \mathrm{~mL}$ was the best volume for optimum results, after which the fluorescence intensity of Ag-NPs was almost of the same values with the increase in $\mathrm{AgNO}_{3}$ volume (Fig. 8a).

\subsubsection{Effect of stabilizer type, concentration, and volume}

Ag-NPs are liable to agglomerate during their synthesis. Thus, Ag-NPs were stabilized by one of two stabilizers: electrostatic stabilizers or steric stabilizers to prevent their agglomeration [2]. Electrostatic stabilizers such as sodium citrate, act by adsorption on the nanoparticles' surface forming an electrical double layer that causes columbic repulsion between the nanoparticles and consequently preventing their agglomeration. While steric stabilizers such as PVP, are characterized by making a protective cap on the nanoparticles' surface and therefore preventing their agglomeration. In this study, it was observed that using the PVP gave higher fluorescence values than sodium citrate. Thus, PVP was chosen to stabilize Ag-NPs and prevent their agglomeration.

Several trials were performed on different concentrations of PVP solution in a similar way to that of $\mathrm{AgNO}_{3}$ solution. As a result, it was noticed that the PVP $(0.14 \%)$ solution was the best-concentrated one for optimum results, after which the increase in the concentration of PVP solution led to a slight decrease in the fluorescence intensity of Ag-NPs. Then, different volumes of PVP solution (0.14\%) were tried at the same reaction conditions. The results revealed that $1 \mathrm{~mL}$ was the best volume for optimum results, after which the fluorescence intensity of Ag-NPs slightly decreased with the increase in PVP volume (Fig. 8b).

\subsubsection{Effect of concentration and volume of $\mathrm{NaOH}$ solution}

During the reduction process of silver ions to Ag-NPs by VANH, the $\mathrm{H}^{+}$ions were produced in the reaction medium. Hence, $\mathrm{NaOH}$ solution was added to provide enough alkalinity to the reaction medium and to 
consume the produced $\mathrm{H}^{+}$ions resulting in hastening of the reaction and promoting the reduction process required for Ag-NPs formation. Consequently, the effect of $\mathrm{NaOH}$ solution should be well studied by testing differently concentrated solutions of $\mathrm{NaOH}$ in a similar way to that of $\mathrm{AgNO}_{3}$ solution. After several trials, it was found that $\mathrm{NaOH}\left(5 \times 10^{-3} \mathrm{M}\right)$ solution was the best-concentrated one for optimum results, after which the increase in $\mathrm{NaOH}$ concentration resulted in a significant decrease in the fluorescence intensity of $\mathrm{Ag}-\mathrm{NPs}$ due to the formation of $\mathrm{Ag}_{2} \mathrm{O}$ black precipitate. Also, different volumes of $\mathrm{NaOH}$ solution $\left(5 \times 10^{-3} \mathrm{M}\right)$ were tested at the same reaction conditions. The results revealed that 1.2 $\mathrm{mL}$ was the best volume for optimum results, after which the increase in $\mathrm{NaOH}$ volume resulted in a gradual small decrease in the fluorescence intensity of Ag-NPs (Fig. 8c).

\subsubsection{Effect of reaction temperature and heating time}

It was observed that the reaction system of the proposed method required heating at $90^{\circ} \mathrm{C}$ in a water bath for a certain time to obtain optimum fluorescence values of Ag-NPs. After which the increase in reaction temperature resulted in a significant decrease in the fluorescence intensity of Ag-NPs due to silver precipitation. Subsequently, different heating times at $90^{\circ} \mathrm{C}$ were tested in a similar way to that of the $\mathrm{AgNO}_{3}$ solution. It was found that heating at $90^{\circ} \mathrm{C}$ for 20 minutes was the best time for optimum fluorescence intensity results, after which the Ag-NPs fluorescence remained constant indicating the end of reaction for Ag-NPs synthesis (Fig. 8d).

\subsubsection{Effect of Britton-Robinson buffer ( $\mathrm{pH}$ and volume)}

After several trials, it was found that Ag-NPs can't be formed in presence of buffer solutions. Consequently, Britton-Robinson buffer solution was added after the formation of Ag-NPs to obtain stable fluorescence intensity values.

So, the effects of $\mathrm{pH}$ ranging from 2 to 12 and volume of added buffer ranging from 0.25 to $2.75 \mathrm{~mL}$ were studied versus the fluorescence intensity at other optimal reaction conditions (Table 1). It was found that the fluorescence intensity of Ag-NPs gradually increased up to $\mathrm{pH} 6$ at which maximum fluorescence intensity was achieved. At high pH values ( $>6)$, the fluorescence intensity of Ag-NPs decreased gradually as a result of Ag-NPs aggregation under alkaline conditions [44]. So, the choice of $\mathrm{pH} 6$ was crucial to obtain optimum and stable fluorescence intensity values (Fig. 8e). Also, the results revealed that $1 \mathrm{~mL}$ of Britton-Robinson buffer solution ( $\mathrm{pH}=6)$ was the best volume for optimum results, after which the fluorescence intensity of Ag-NPs was almost of the same values with the increase in buffer volume (Fig. 8f).

\subsubsection{Effect of diluting solvent}

Upon dilution with different solvents such as bi-distilled water, acetonitrile, methanol, acetone, ethanol, and 2-propanol, bi-distilled water was observed to give the highest fluorescence intensity value (Fig. $\mathbf{8 g}$ ). Hence, bi-distilled water was the diluting solvent of choice throughout this study.

\section{Method Validation}


According to ICH guidelines [45], the proposed fluorimetric method was validated yielding satisfactory results.

\subsection{Linearity and range}

According to the general procedure of the proposed method (Section 3.1) and by applying the optimized conditions of the experiment (Table 1), the calibration graph was obtained by plotting the fluorescence intensity values against the corresponding VANH concentrations over the range (1-36 ng/mL). The correlation coefficient and other regression parameters were computed (Table 3 ). Each prepared concentration of VANH was measured three times. 
Table 3

Assay parameters for the green analysis of VANH by the proposed fluorimetric method.

\begin{tabular}{|c|c|}
\hline Parameters & VANH \\
\hline Concentration range & $1-36(\mathrm{ng} / \mathrm{mL})$ \\
\hline Correlation coefficient & 0.9999 \\
\hline Slope & 30.45 \\
\hline Intercept & -6.50 \\
\hline S.D of intercept ${ }^{a}$ & 2.75 \\
\hline $\operatorname{LOD}^{\mathrm{b}}$ & $0.30(\mathrm{ng} / \mathrm{mL})$ \\
\hline $\mathrm{LOQ}^{\mathrm{b}}$ & $0.90(\mathrm{ng} / \mathrm{mL})$ \\
\hline \multicolumn{2}{|l|}{ Accuracy } \\
\hline Mean \pm SD & $100.89 \pm 0.50$ \\
\hline RSD\% & 0.50 \\
\hline $\mathrm{Er} \%{ }^{\mathrm{c}}$ & 0.33 \\
\hline \multicolumn{2}{|l|}{ Intra-day precision ${ }^{d}$} \\
\hline Mean \pm SD & $100.60 \pm 0.29$ \\
\hline RSD $\%$ & 0.29 \\
\hline $\mathrm{Er} \% \mathrm{c}$ & 0.31 \\
\hline \multicolumn{2}{|l|}{ Inter-day precision ${ }^{\mathrm{e}}$} \\
\hline Mean \pm SD & $100.61 \pm 0.35$ \\
\hline $\mathrm{RSD} \%$ & 0.35 \\
\hline $\mathrm{Er} \% \mathrm{c}$ & 0.25 \\
\hline
\end{tabular}

a Standard deviation of intercept.

${ }^{b} \mathrm{LOD}=(\mathrm{SD}$ of the response/slope $) \times 3.3 ; \mathrm{LOQ}=(\mathrm{SD}$ of the response/slope $) \times 10$.

${ }^{\mathrm{c}}$ Relative error percentage.

${ }^{d}$ The intra-day analysis, average of three different concentrations of VANH $(10,20$, and $30 \mathrm{ng} / \mathrm{mL})$ repeated three times within the day.

e The inter-day analysis, average of three different concentrations of VANH $(10,20$, and $30 \mathrm{ng} / \mathrm{mL})$ repeated three times in three consecutive days. 


\subsection{LOD and LOQ}

To estimate the proposed fluorimetric method sensitivity, LOD and LOQ were computed and listed in Table 3. The exhibited results revealed the ultrasensitivity of the proposed method for VANH determination. For computing of LOD and LOQ, the following equations were utilized:

$\operatorname{LOD}=(3.3 \times \sigma) / \mathrm{S}$.

$\mathrm{LOQ}=(10 \times \sigma) / \mathrm{S}$.

Where $(\sigma)$ is the standard deviation of the response.

$(\mathrm{S})$ is the calibration graph slope.

\subsection{Accuracy and precision}

To compute the accuracy and precision at both intra- and inter-day levels, three different standard concentrations of VANH were prepared to cover the low, medium, and higher ranges of the calibration curve $(10,20$, and $30 \mathrm{ng} / \mathrm{mL}$ ) and subsequently analyzed by the proposed method in triplicate. The intraday analysis (repeatability) was done on the same day while the inter-day one (intermediate precision) was operated on three consecutive days. The obtained accuracy results expressed as mean of percentage recoveries and standard deviation were satisfactory (Table 3 ). While the calculated values of relative standard deviations (RSD \%) didn't exceed $2 \%$ revealing the excellent precision of the proposed method for both intra- and inter-day levels as presented in Table 3, where the percentage relative errors (Er $\%)$ were also listed.

\subsection{Robustness}

To assess the robustness of the proposed method, each parameter of the reaction system was changed separately with a small value keeping the other parameters constant. The results as presented in (Table 4) revealed that the proposed method persisted unaffected by the deliberated small variations in the reaction parameters indicating the robustness of this method. 
Table 4

Robustness study of the proposed fluorimetric method using pure $(20 \mathrm{ng} / \mathrm{mL})$ of VANH.

\begin{tabular}{|ll|}
\hline Condition & Results \\
\cline { 2 - 3 } & Recovery\% ${ }^{\mathrm{a}} \pm \mathrm{SD}$ \\
\hline Optimum condition & $100.79 \pm 1.02$ \\
\hline $\mathrm{AgNO}_{3}\left(3 \times 10^{-3} \mathrm{M}\right)(1.1 \mathrm{~mL})$ & $98.64 \pm 0.36$ \\
\hline $\mathrm{AgNO}_{3}\left(3 \times 10^{-3} \mathrm{M}\right)(1.3 \mathrm{~mL})$ & $100.16 \pm 0.53$ \\
\hline $\mathrm{PVP}(0.14 \%)(0.9 \mathrm{~mL})$ & $98.93 \pm 0.37$ \\
\hline $\mathrm{PVP}(0.14 \%)(1.1 \mathrm{~mL})$ & $98.76 \pm 0.99$ \\
\hline $\mathrm{NaOH}\left(5 \times 10^{-3} \mathrm{M}\right)(1.1 \mathrm{~mL})$ & $98.78 \pm 1.03$ \\
\hline $\mathrm{NaOH}\left(5 \times 10^{-3} \mathrm{M}\right)(1.3 \mathrm{~mL})$ & $99.17 \pm 0.34$ \\
\hline Heating time $\left(\right.$ at $\left.90^{\circ} \mathrm{C}\right)(18 \mathrm{~min})$ & $98.35 \pm 0.33$ \\
\hline Heating time $\left(\right.$ at $\left.90^{\circ} \mathrm{C}\right)(22 \mathrm{~min})$ & $99.78 \pm 0.39$ \\
\hline Britton-Robinson buffer $(\mathrm{pH}=5.8)$ & $98.46 \pm 0.66$ \\
\hline Britton-Robinson buffer $(\mathrm{pH}=6.2)$ & $99.20 \pm 0.62$ \\
\hline Britton-Robinson buffer $(\mathrm{pH}=6)(0.9 \mathrm{~mL})$ & $100.34 \pm 1.13$ \\
\hline Britton-Robinson buffer $(\mathrm{pH}=6)(1.1 \mathrm{~mL})$ & $101.27 \pm 1.05$ \\
\hline a Mean of three determinations. & \\
\hline
\end{tabular}

\section{Method Application}

\subsection{Pharmaceutical application}

The proposed method was successfully applied for quantitative VANH analysis in its commercial Vancomycine ${ }^{\circledR}$ Mylan vial. The values of percentage recoveries mean and relative standard deviation presented in Table 5 were satisfactory and in good agreement with the cited drug label claim without pharmaceutical additives interference. Moreover, the tabulated results ascertained the suitability of the proposed method for the routine analysis of VANH in QC laboratories. The proposed method's validity was also checked by applying the standard addition technique yielding satisfactory results as presented in Table 5. 
Table 5

Determination of VANH by the proposed fluorimetric method in Vancomycine® Mylan vial and application of standard addition technique.

\begin{tabular}{|c|c|c|c|c|c|}
\hline \multirow[t]{2}{*}{ Product } & \multirow{2}{*}{$\begin{array}{l}\text { Recovery } \%^{\mathrm{b}} \pm \\
\text { RSD }\end{array}$} & \multicolumn{4}{|c|}{ Standard addition } \\
\hline & & $\begin{array}{l}\text { Taken } \\
(\mathrm{ng} / \mathrm{mL})\end{array}$ & $\begin{array}{l}\text { Added } \\
\text { (ng/mL) }\end{array}$ & $\begin{array}{l}\text { Found } \\
\text { (ng/mL) }\end{array}$ & Recovery\% ${ }^{\mathrm{c}}$ \\
\hline \multirow{6}{*}{$\begin{array}{l}\text { Vancomycine }{ }^{\circledR} \\
\text { Mylan }^{a}\end{array}$} & \multirow[t]{6}{*}{$100.64 \pm 0.61$} & \multirow[t]{6}{*}{10} & 5 & 5.06 & 101.20 \\
\hline & & & 10 & 9.92 & 99.20 \\
\hline & & & 15 & 15.23 & 101.53 \\
\hline & & & 20 & 19.91 & 99.55 \\
\hline & & & 25 & 25.11 & 100.44 \\
\hline & & & \multicolumn{2}{|c|}{ Mean \pm RSD } & $\begin{array}{l}100.38 \pm \\
1.01\end{array}$ \\
\hline \multicolumn{6}{|c|}{ a Vancomycine® Mylan vial labeled to contain 500 mg of VANH; batch number (B1527). } \\
\hline \multicolumn{6}{|c|}{${ }^{\mathrm{b}}$ Mean of five determinations. } \\
\hline
\end{tabular}

\subsection{Biological fluids application}

According to the pharmacokinetic study of VANH [3], it was found that the VANH $C_{\max }$ was $60 \mu \mathrm{g} / \mathrm{mL}$ after a one-hour infusion of vancomycin (1-gm dose), and about 80 to $90 \%$ of this dose was recovered unchanged in the urine within 24 hours. The attained ultrasensitivity by the proposed method permitted the determination of VANH in spiked human plasma and urine at ultra-trace quantities. Also, the presented satisfying results in Table 6 proved that the proposed method can be utilized not only in the monitoring but also in the pharmacokinetic study of VANH without any interference by the matrix of plasma or urine. 
Table 6

Determination of VANH by the proposed fluorimetric method in spiked human plasma and urine.

\begin{tabular}{|llllll|}
\hline Plasma & \multicolumn{5}{c|}{ Urine } \\
\hline $\begin{array}{l}\text { Added } \\
(\mathrm{ng} / \mathrm{mL})\end{array}$ & $\begin{array}{l}\text { Found } \\
(\mathrm{ng} / \mathrm{mL})\end{array}$ & Recovery\% $\left.{ }^{\mathrm{a}}\right)$ & $\begin{array}{l}\text { Added } \\
(\mathrm{ng} / \mathrm{mL})\end{array}$ & $\begin{array}{l}\text { Found } \\
(\mathrm{ng} / \mathrm{mL})\end{array}$ & Recovery\% ${ }^{\mathrm{a}}$ \\
\hline 10 & 10.13 & 101.30 & 10 & 9.98 & 99.80 \\
15 & 15.08 & 100.53 & 15 & 14.81 & 98.73 \\
\hline 20 & 20.39 & 101.95 & 20 & 19.74 & 98.70 \\
\hline 25 & 24.73 & 98.92 & 25 & 25.29 & 101.16 \\
\hline 30 & 30.18 & 100.60 & 30 & 29.62 & 98.73 \\
\hline Mean \pm SD & & $100.66 \pm$ & Mean \pm SD & & $99.42 \pm$ \\
\hline
\end{tabular}

\section{Statistical Analysis}

The obtained results by the proposed method for VANH analysis in its pure form were statistically compared with those obtained by the reported HPLC method [21]. So, $t$-and F-values were computed and listed in Table 7 where the computed values didn't exceed the theoretical ones. Consequently, no significant differences in results were found between the proposed method and the reported one indicating the high accuracy and precision of the proposed method. 
Table 7

Statistical comparison between the proposed and reported HPLC [21] methods for VANH analysis in its pure form.

\begin{tabular}{|lll|}
\hline $\begin{array}{l}\text { Methods } \\
\text { Parameters }\end{array}$ & Proposed fluorimetric method & Reported HPLC method [21] \\
\hline Mean & 100.34 & 99.90 \\
\hline SD & 0.59 & 0.81 \\
\hline N & 6 & 6 \\
\hline Variance & 0.35 & 0.66 \\
\hline Student's & 1.08 & -- \\
t-test $(2.23)^{a}$ & & -- \\
\hline F- value (5.05) & 0.53 & \\
\hline a The parentheses contain the corresponding theoretical $t$ and F values at $(P=0.05)$. \\
\hline
\end{tabular}

\section{Conclusion}

AgNPs-enhanced fluorescence technique was proposed for the determination of VANH at ultra-sensitive levels which depended on enhancing the fluorescence signal of VANH by the formation of Ag-NPs. This proposed technique was found to have higher sensitivity and lower limit of detection than the comparison method. Moreover, it was successfully applied to commercial vials with excellent recovery and good reproducibility. The rapidness and easiness of the proposed method allowed its application for routine VANH analysis in QC laboratories. Also, the proposed method is suitable for in-vitro routine determination of VANH in spiked human plasma and urine in clinical laboratories that seek an economic, sensitive, and environmentally safe method. Accordingly, it is considered a reliable approach for further clinical studies. The presented effort expands the scope of colloidal Ag-NPs application in the analytical field.

\section{Declarations}

\section{- Funding}

I declare that no funds, grants, or other support were received during the preparation of this manuscript.

\section{- Competing Interests}

I have no relevant financial or non-financial interests to disclose. 


\section{- Ethics approval}

This study was performed in line with the principles of the Declaration of Helsinki. Approval was granted by the Ethics Committee at Faculty of Pharmacy, Zagazig University (1/10/2021/No. ZU/01/10/2021).

\section{- Consent to participate}

Informed consent was obtained from all individual participants included in the study.

\section{- Consent to publish}

I affirm that human research participants provided informed consent for publication.

\section{- Data availability}

All data generated or analyzed during this study are included in this article.

\section{- Code availability}

Not applicable.

\section{- Author Contributions}

I'm the only author for this research (Ahmed R. Mohamed).

\section{References}

1. L.A. Austin, M.A. Mackey, E.C. Dreaden, M.A. El-Sayed, The optical, photothermal, and facile surface chemical properties of gold and silver nanoparticles in biodiagnostics, therapy, and drug delivery, Archives of Toxicology. 88 (2014) 1391-1417.

2. M.M. Ayad, H.E. Abdellatef, M.M. Hosny, Y.A. Sharaf, Determination of etilefrine hydrochloride, fenoterol hydrobromide, salbutamol sulphate and estradiol valerate using surface plasmon resonance band of silver nanoparticles, International Journal of Pharmacy and Pharmaceutical Sciences. 7 (2015) 327-333.

3. A. Brayfield, Martindale: the complete drug reference, Pharmaceutical press London, 38th ed., (2014) 384-386.

4. A.M. El-Didamony, A.S. Amin, A.K. Ghoneim, A.M. Telebany, Indirect spectrophotometric determination of gentamicin and vancomycin antibiotics based on their oxidation by potassium permanganate, Central European Journal of Chemistry. 4 (2006) 708-722.

5. A.R. Junior, M.M.D.C. Vila, M. Tubino, Green spectrophotometric method for the quantitative analysis of vancomycin in pharmaceuticals and comparison with HPLC, Analytical Letters. 41 (2008) 822- 
836.

6. S.M. El-Ashry, F. Belal, M.M. El-Kerdawy, D.R. El Wasseef, Spectrophotometric determination of some phenolic antibiotics in dosage forms, Microchimica Acta. 135 (2000) 191-196.

7. M.A. Marzouq, B.I. Salman, S.A. Hussein, M.F.B. Ali, Utility of fluorescamine-based approach for highly sensitive spectrofluorimetric determination of ceftazidime and vancomycin in pharmaceuticals and real human plasma, Microchemical Journal. 145 (2019) 218-225.

8. M.K.S. El-Din, F. Ibrahim, A.K. El-Deen, K. Shimizu, Stability-indicating spectrofluorimetric method with enhanced sensitivity for determination of vancomycin hydrochloride in pharmaceuticals and spiked human plasma: Application to degradation kinetics, Journal of Food and Drug Analysis. 26 (2018) 834-841.

9. M.A. Marzouq, B.I. Salman, S.A. Hussein, M.F.B. Ali, Hantzsch reaction approach for determination of teicoplanin and vancomycin in real human plasma: Application to pharmaceutical preparations and to synthetic mixture with rifampicin for drug-resistant strain of Staphylococcus aureus, Microchemical Journal. 147 (2019) 25-29.

10. A.A.S. Gill, S. Singh, N. Agrawal, Z. Nate, T.E. Chiwunze, N.B. Thapliyal, R. Chauhan, R. Karpoormath, A poly (acrylic acid)-modified copper-organic framework for electrochemical determination of vancomycin, Microchimica Acta. 187 (2020) 1-9.

11. F. Belal, S.M. El-Ashry, M.M. El-Kerdawy, D.R. El-Wasseef, Voltametric determination of vancomycin in dosage forms through treatment with nitrous acid, Arzneimittel-forschung. 51 (2001) 763-768.

12. M. Hadi, T. Mollaei, Electroanalytical determination of vancomycin at a graphene-modified electrode: Comparison of electrochemical property between graphene, carbon nanotube, and carbon black, Electroanalysis. 31 (2019) 1224-1228.

13. L.-Q. Hu, C.-L. Yin, Y.-H. Du, Z.-P. Zeng, Simultaneous and direct determination of vancomycin and cephalexin in human plasma by using HPLC-DAD coupled with second-order calibration algorithms, Journal of Analytical Methods in Chemistry. 2012 (2012) 1-8.

14. M.J. de Jesús Valle, F.G. López, A.S. Navarro, Development and validation of an HPLC method for vancomycin and its application to a pharmacokinetic study, Journal of Pharmaceutical and Biomedical Analysis. 48 (2008) 835-839.

15. K.J.V. López, D.F. Bertoluci, K.M. Vicente, A.M. Dell'Aquilla, S.R.C.J. Santos, Simultaneous determination of cefepime, vancomycin and imipenem in human plasma of burn patients by highperformance liquid chromatography, Journal of Chromatography B. 860 (2007) 241-245.

16. M. Saito, T. Santa, M. Tsunoda, H. Hamamoto, N. Usui, An automated analyzer for vancomycin in plasma samples by column-switching high-performance liquid chromatography with UV detection, Biomedical Chromatography. 18 (2004) 735-738.

17. P. Favetta, J. Guitton, N. Bleyzac, C. Dufresne, J. Bureau, New sensitive assay of vancomycin in human plasma using high-performance liquid chromatography and electrochemical detection, Journal of Chromatography B: Biomedical Sciences and Applications. 751 (2001) 377-382. 
18. T. de M. Lima, K.S. Seba, J.C.S. Gonçalves, F.L.L. Cardoso, R. de C.E. Estrela, A rapid and simple HPLC method for therapeutic monitoring of vancomycin, Journal of Chromatographic Science. 56 (2018) 115-121.

19. G. Ye, X. Cai, B. Wang, Z. Zhou, X. Yu, W. Wang, J. Zhang, Y. Wang, J. Dong, Y. Jiang, Simultaneous determination of vancomycin and ceftazidime in cerebrospinal fluid in craniotomy patients by highperformance liquid chromatography, Journal of Pharmaceutical and Biomedical Analysis. 48 (2008) 860-865.

20. P. Milla, F. Ferrari, E. Muntoni, M. Sartori, C. Ronco, S. Arpicco, Validation of a simple and economic HPLC-UV method for the simultaneous determination of vancomycin, meropenem, piperacillin and tazobactam in plasma samples, Journal of Chromatography B. 1148 (2020) 122151.

21. D. Ramadon, A.J. Courtenay, A.D. Permana, I.A. Tekko, E. McAlister, M.T.C. McCrudden, H.O. McCarthy, R.F. Donnelly, A sensitive HPLC-UV method for quantifying vancomycin in biological matrices: Application to pharmacokinetic and biodistribution studies in rat plasma, skin and lymph nodes, Journal of Pharmaceutical and Biomedical Analysis. 189 (2020) 113429.

22. M. Liu, Z.-H. Yang, G.-H. Li, A novel method for the determination of vancomycin in serum by highperformance liquid chromatography-tandem mass spectrometry and its application in patients with diabetic foot infections, Molecules. 23 (2018) 2939.

23. F. Ibrahim, M.S. Elgawish, E. Mehana, S.M. El-Adl, M.M. Baraka, S.M. Ibrahim, M.M. Sebaiy, Toxicity profile and pharmacokinetic study of antibiotic mixtures, gentamicin and vancomycin, in rat plasma by ecofriendly liquid chromatography coupled tandem mass spectrometry, Chemical Research in Toxicology. 33 (2020) 2647-2658.

24. C. Cheng, S. Liu, D. Xiao, J. Hollembaek, L. Yao, J. Lin, S. Hansel, LC-MS/MS method development and validation for the determination of polymyxins and vancomycin in rat plasma, Journal of Chromatography B. 878 (2010) 2831-2838.

25. N.B. Andriguetti, L.L. Lisboa, S.R. Hahn, L.R. Pagnussat, M. V Antunes, R. Linden, Simultaneous determination of vancomycin and creatinine in plasma applied to volumetric absorptive microsampling devices using liquid chromatography-tandem mass spectrometry, Journal of Pharmaceutical and Biomedical Analysis. 165 (2019) 315-324.

26. L. Bai, Q. Fei, F. Lei, R. Luo, Q. Ma, M. Dai, H. Zhang, N. He, Comparative analysis of pharmacokinetics of vancomycin hydrochloride in rabbits after ocular, intragastric, and intravenous administration by LC-MS/MS, Xenobiotica. 50 (2020) 1461-1468.

27. S.L. Parker, Y.C. Guerra Valero, J.L. Ordóñez Mejia, C. Roger, J. Lipman, J.A. Roberts, S.C. Wallis, An LC-MS/MS method to determine vancomycin in plasma (total and unbound), urine and renal replacement therapy effluent, Bioanalysis. 9 (2017) 911-924.

28. H. Brozmanová, I. Kacířová, R. Uřinovská, P. Šištík, M. Grundmann, New liquid chromatographytandem mass spectrometry method for routine TDM of vancomycin in patients with both normal and impaired renal functions and comparison with results of polarization fluoroimmunoassay in light of varying creatinine concentrations, Clinica Chimica Acta. 469 (2017) 136-143. 
29. L. Javorska, L.K. Krcmova, P. Solich, M. Kaska, Simple and rapid quantification of vancomycin in serum, urine and peritoneal/pleural effusion via UHPLC-MS/MS applicable to personalized antibiotic dosing research, Journal of Pharmaceutical and Biomedical Analysis. 142 (2017) 59-65.

30. S. Barco, E. Castagnola, I. Gennai, L. Barbagallo, A. Loy, G. Tripodi, G. Cangemi, Ultra high performance liquid chromatography-tandem mass spectrometry vs. commercial immunoassay for determination of vancomycin plasma concentration in children. Possible implications for everyday clinical practice, Journal of Chemotherapy. 28 (2016) 395-402.

31. Y. Fan, X. Peng, H. Wu, X. Liang, Y. Chen, B. Guo, J. Zhang, Simultaneous separation and determination of vancomycin and its crystalline degradation products in human serum by ultra high performance liquid chromatography tandem mass spectrometry method and its application in therapeutic drug monitoring, Journal of Separation Science. 43 (2020) 3987-3994.

32. A.C.C. da Silva, L. de L.F. Lizot, M.F. Bastiani, M.V. Antunes, N. Brucker, R. Linden, Ready for TDM: Simultaneous quantification of amikacin, vancomycin and creatinine in human plasma employing ultra-performance liquid chromatography-tandem mass spectrometry, Clinical Biochemistry. 70 (2019) 39-45.

33. Y. Fan, X. Peng, J. Yu, X. Liang, Y. Chen, X. Liu, B. Guo, J. Zhang, An ultra-performance liquid chromatography-tandem mass spectrometry method to quantify vancomycin in human serum by minimizing the degradation product and matrix interference, Bioanalysis. 11 (2019) 941-955.

34. A. Musenga, R. Mandrioli, V. Zecchi, B. Luppi, S. Fanali, M.A. Raggi, Capillary electrophoretic analysis of the antibiotic vancomycin in innovative microparticles and in commercial formulations, Journal of Pharmaceutical and Biomedical Analysis. 42 (2006) 32-38.

35. J. Wang, Y. Cao, S. Wu, S. Wang, X. Zhao, T. Zhou, Y. Lou, G. Fan, Determination of vancomycin in human serum by cyclodextrin-micellar electrokinetic capillary chromatography (CD-MEKC) and application for PDAP Patients, Molecules. 22 (2017) 538.

36. K.C. Chong, L.Y. Thang, J.P. Quirino, H.H. See, Monitoring of vancomycin in human plasma via portable microchip electrophoresis with contactless conductivity detector and multi-stacking strategy, Journal of Chromatography A. 1485 (2017) 142-146.

37. T. Kitahashi, I. Furuta, Determination of vancomycin in human serum by micellar electrokinetic capillary chromatography with direct sample injection, Clinica Chimica Acta. 312 (2001) 221-225.

38. I. Chianella, A. Guerreiro, E. Moczko, J.S. Caygill, E. V Piletska, I.M.P. De Vargas Sansalvador, M.J. Whitcombe, S.A. Piletsky, Direct replacement of antibodies with molecularly imprinted polymer nanoparticles in ELISA- development of a novel assay for vancomycin, Analytical Chemistry. 85 (2013) 8462-8468.

39. B.H. Ackerman, H.G. Berg, R.G. Strate, J.C. Rotschafer, Comparison of radioimmunoassay and fluorescent polarization immunoassay for quantitative determination of vancomycin concentrations in serum, Journal of Clinical Microbiology. 18 (1983) 994-995.

40. C. Xu, Q. Han, S. Dong, X. Liu, X. Liu, Establishment of an ultrasensitive indirect competitive timeresolved fluoroimmunoassay for vancomycin determination, Food and Agricultural Immunology. 30 
(2019) 862-877.

41. K. Riddhi, S.Desai, Green analytical chemistry and its matrices-An initiative for a greener and safer tomorrow, International Journal of Pharmaceutical Sciences Review and Research. 55 (2019) 24-31.

42. A. Gałuszka, Z.M. Migaszewski, P. Konieczka, J. Namieśnik, Analytical eco-scale for assessing the greenness of analytical procedures, TrAC Trends in Analytical Chemistry. 37 (2012) 61-72.

43. J. Płotka-Wasylka, A new tool for the evaluation of the analytical procedure: Green Analytical Procedure Index, Talanta. 181 (2018) 204-209.

44. Y. Wang, J. Zhou, T. Wang, Enhanced luminescence from europium complex owing to surface plasmon resonance of silver nanoparticles, Materials Letters. 62 (2008) 1937-1940.

45. ICH. Q2A (R1). Validation of analytical procedures: text and methodology. International Conference on Harmonization. Geneva, Switzerland: IFPMA, 2005.

\section{Figures}

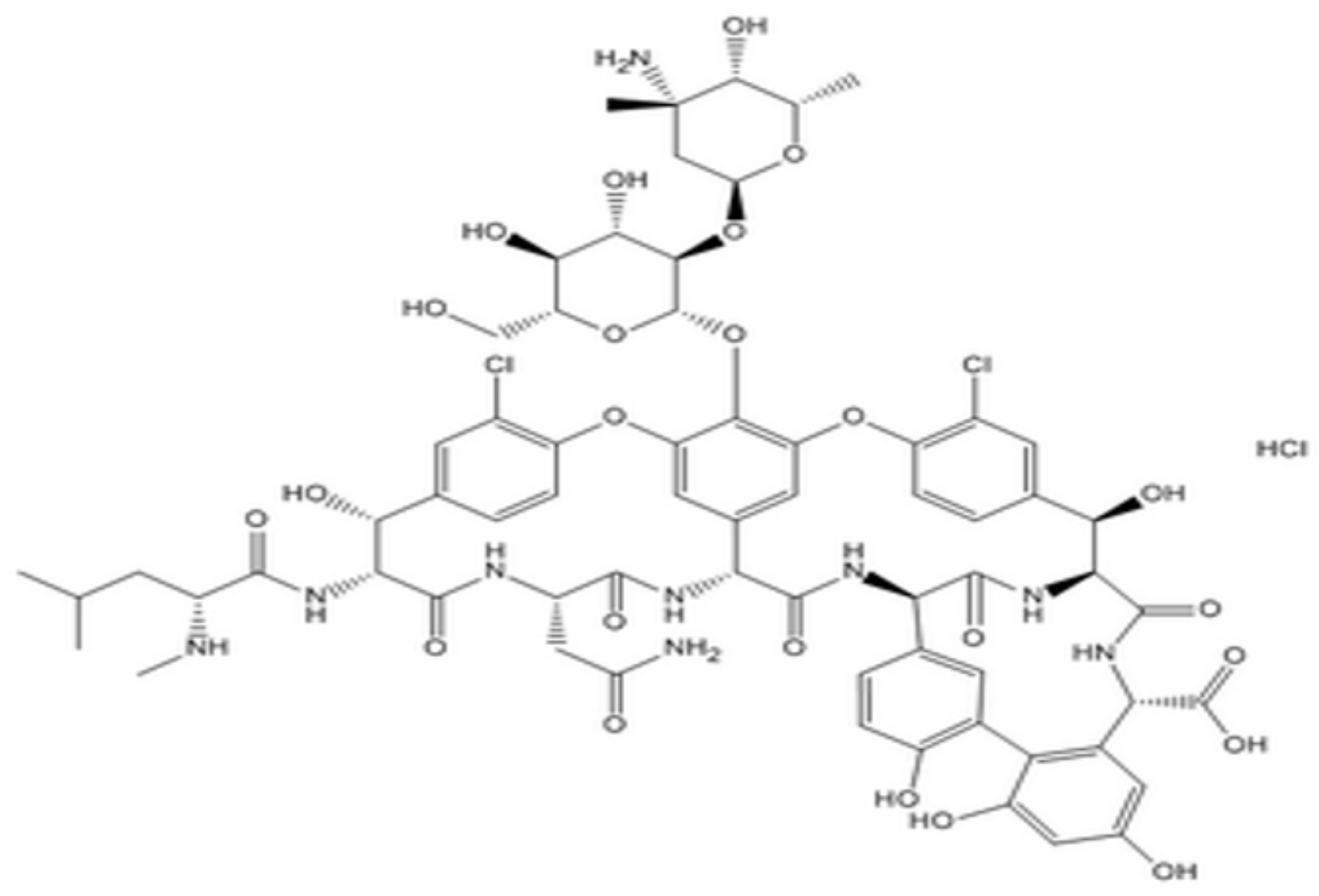

Figure 1

Chemical structure of vancomycin hydrochloride. 


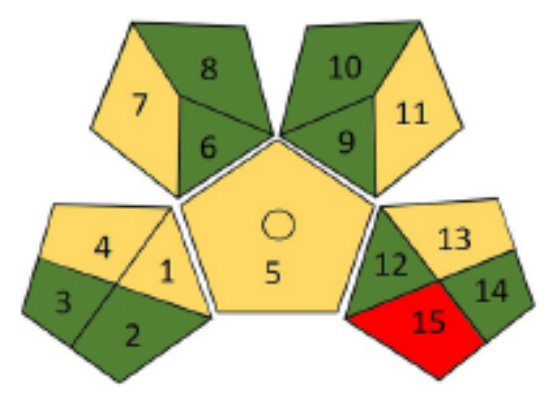

Figure 2

Greenness assessment profile of the proposed fluorimetric method using the GAPI tool.

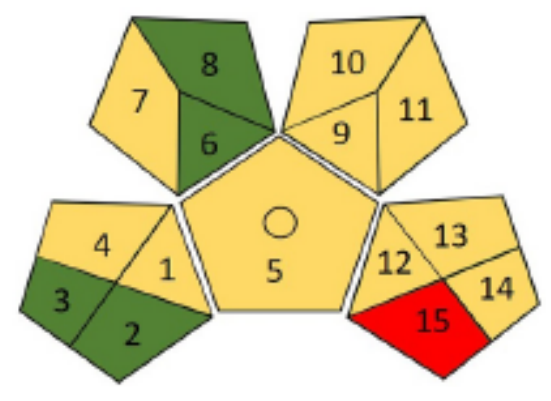

Figure 3

Greenness assessment profile of the reported HPLC method using the GAPI tool.
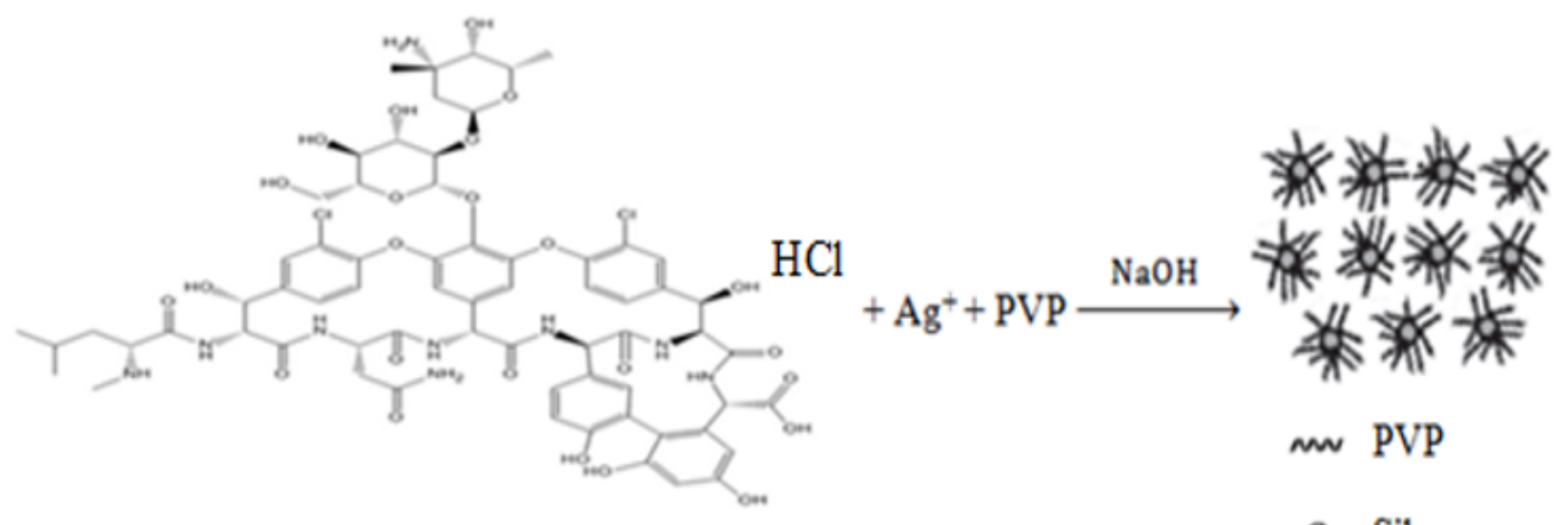

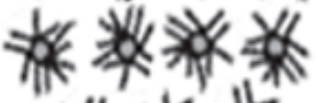

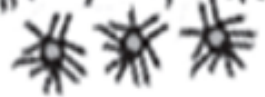

$m$ PVP

- Silver nanoparticles

\section{Figure 4}

Silver ions reduction by VANH to stoichiometrically equivalent quantity of Ag-NPs. 


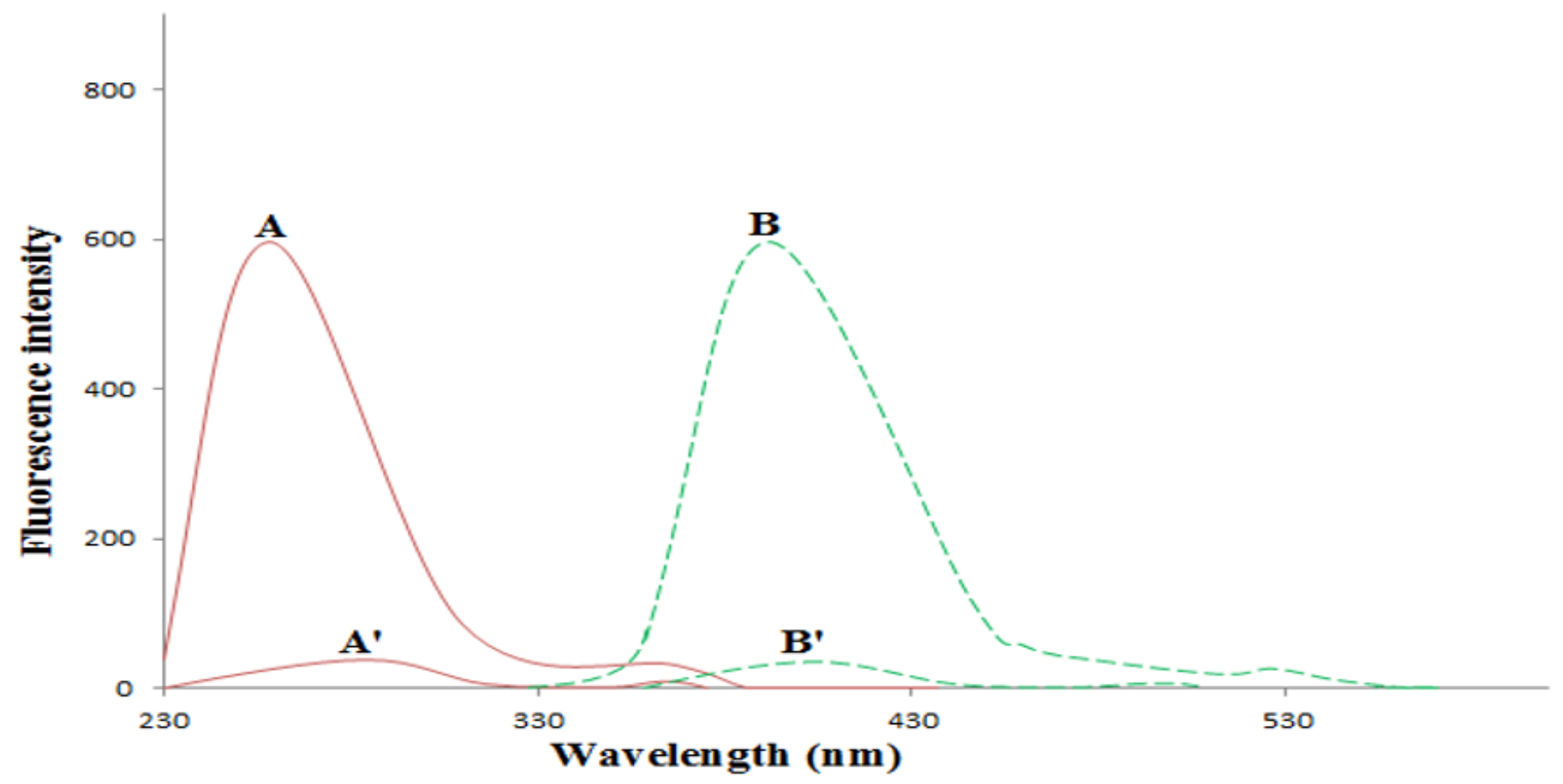

Figure 5

Excitation (A) and emission (B) spectra of the prepared Ag-NPs using $(20 \mathrm{ng} / \mathrm{mL}) \mathrm{VANH}$ against the blank reagent $\left(A^{\prime}\right.$ and $\left.B^{\prime}\right)$ in bi-distilled water as a diluting solvent.

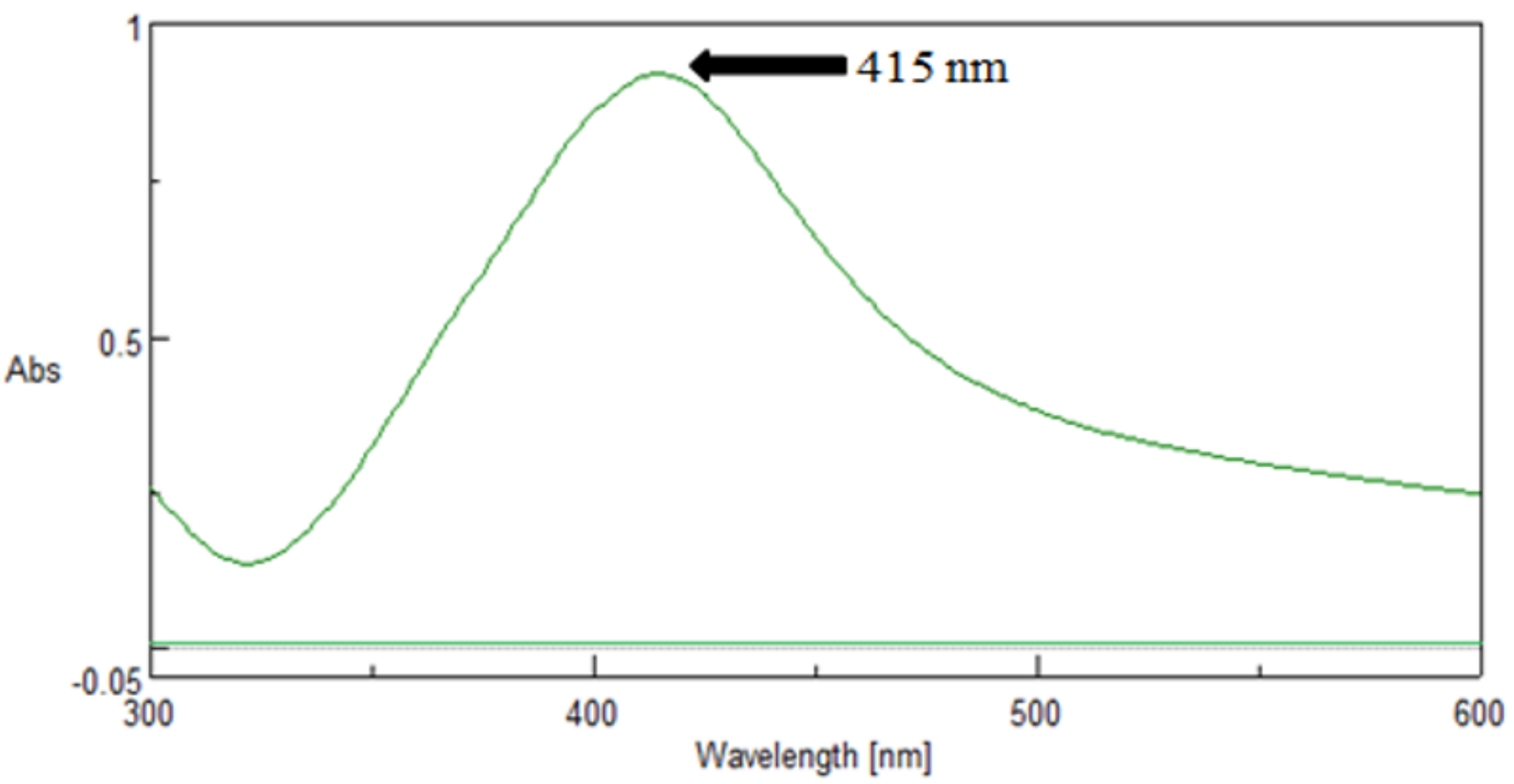

Page $24 / 25$ 
Figure 6

Absorbance spectrum of Ag-NPs developed in presence of VANH $(2 \mu \mathrm{g} / \mathrm{mL})$.

Figure 7

TEM micrograph of Ag-NPs formed in the presence of VANH.

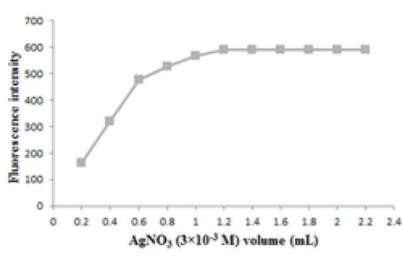

(a)

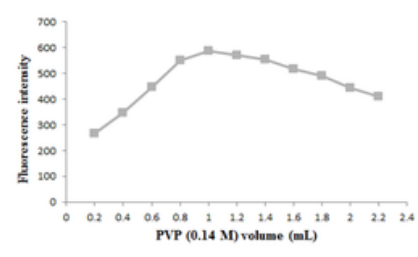

(b)
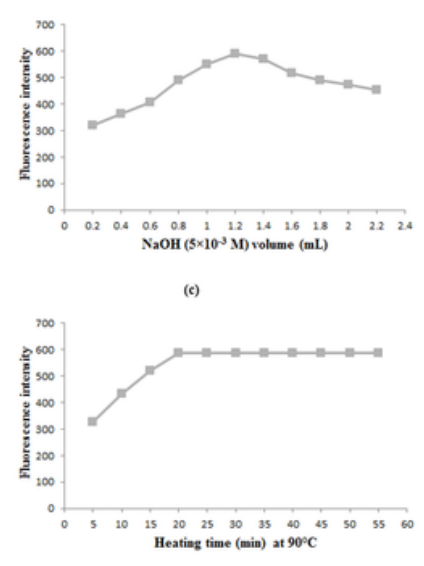

(d)

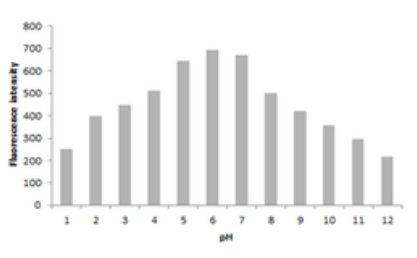

(e)

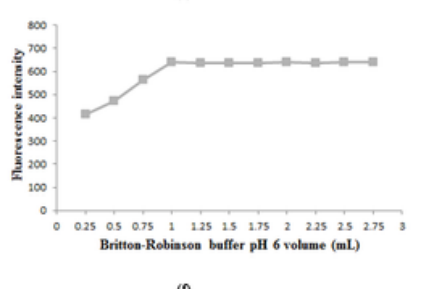

()

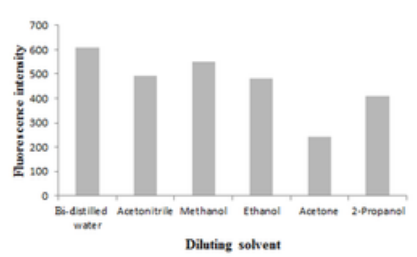

Figure 8

TEM micrograph of Ag-NPs formed in the presence of VANH. 